\title{
Adolescent experience with unwanted pregnancy: a scoping review
}

\author{
Ngaisah Tri Rahayu $^{1 *}$, Mufdlillah ${ }^{2}$, Farida Kartini $^{3}$ \\ ${ }^{1,2,3}$ Universitas ‘Aisyiyah Yogyakarta, j1.Siliwangi No.63 Mlangi Nogotirto Sleman, Yogyakarta (55292), Indonesia \\ 1aisahrahayu17@gmail.com*; ${ }^{2}$ mufdlillah@ stikes@gmail.com; ${ }^{3}$ faridakartini@unisayogya.ac.id \\ *corresponding author
}

Submission date: 23 Maret 2021, Receipt date: 20 April 2021, Publication date: 1 Juli 2021

\begin{abstract}
Teenagers who experience unwanted pregnancy will drop out of school, not accept pregnancy, be ostracized, and plan to have an abortion. This research is a scoping review study that refers to Arskey and Omalley. The databases are Pubmed, Proquest, Sciendirect and Wiley. Critical appraisal using JBI (Joanna Briggs Institute) is grade A with 5 articles and grade B with 2 articles. Psychological impact is an emotional initial reaction, shocked and angry, feel hopeless, and intend to commit suicide because she can not continue her education so that it requires support from family, friends, spouse and the environment.
\end{abstract}

Keywords: experience, adolescenct, unwanted pregnancy

\section{INTRODUCTION}

Global problems related to pregnancy in adolescents aged 15-19 years reached 16 million, and the pregnancy of children under 15 years of age as many as one million. Births in children aged 15-19 years are 50 per 1,000 (UNFPA, 2019). Adolescent pregnancy has an impact on maternal and infant health, especially in areas with low health systems. Complications of pregnancy and childbirth are the leading causes of death in women aged 15-19 years (WHO, 2014). Meanwhile, according to the WHO (World Health Organization) teenage pregnancy occurs in high, middle, and low countries. In developing countries, it is estimated that 12 million adolescents under the age of 15 gave birth to as many as 777,000 and as many as 21 million adolescents aged 15-19 became pregnant due to unwanted pregnancies. (WHO, 2020).

Unwanted pregnancies are defined as false or unwanted pregnancies and cause public health problems (Finer \& Zolna, 2020). Pregnancy in adolescents is associated with medical problems. Teenage pregnancy is not a risky pregnancy and can pose a risk to pregnant teenagers under the age of 15 (Kirchengast, 2016). Unwanted pregnancies among adolescents lead to high rates of spontaneous miscarriage, premature labor and low birth weight. Complications of pregnancy in adolescents cause death in adolescents and can cause tremendous psychological stress (Fahmida Shirin Papri, Zubaida Khanam, Sarwat Ara, 2016). 
The risk factor for unwanted pregnancy is teenagers who have multiple partners who often do not use contraception during intercourse. A lack of knowledge about the proper methods and use of contraceptives causes adolescents to choose to perform abortions (Lidaka et al., 2015). Pregnancy among adolescents before marriage is a serious problem that is if undergoing a relationship without any commitment. Adolescents who experience unwanted pregnancies will experience dropouts, not acceptable pregnancy by a spouse, be ostracized in the surrounding environment, and plan unsafe abortions (Soura et al., 2018).

There are several factors that affect unwanted pregnancy, namely intrapersonal, interpersonal, organizational and contextual. Intrapersonal factors are lack of knowledge about contraception, lack of education about sex, and reproductive health. The interpersonal factor is the lack of communication in spouses, parents and peers to sexuality problems. Organizational factors include low education and access to reproductive health services and contextual factors include gender inequality, cultural norms, and migration (Tuan, 2017). The experience of pregnancy experienced by teenagers when they first learned of their pregnancy, the teenager decided to hide from the parents and terminate the pregnancy by abortion. Teenagers choose to perform abortions performed in an unsafe manner. After performing the abortion the teenager experienced remorse and guilt on him (Domingos et al., 2013).

Barriers to accessing family planning information are lack of knowledge about contraceptive use, lack of sexuality education in schools, lack of health care, lack of policies in dealing with pregnancy in adolescents and contraceptive side effects. Unwanted pregnancies in adolescents are partly due to not using contraception during sexual intercourse (Mandy S. Colesa \& , Kevin K. Makinob, 2012). Efforts in pregnancy prevention are provided with services for contraception. Contraceptive services include a wide range of knowledge about contraceptives such as selecting safe-to-use contraceptives, providing counseling on the correct use of contraceptives, and providing a choice of health care contraceptive methods that can be done in place or place of reference if necessary (CDC, 2019).

This review focuses on identifying adolescent experiences with unwanted pregnancies. The knowledge gained from this study has an important meaning in allowing health workers who deal with adolescents who are experiencing unwanted pregnancies to understand important aspects that should be reviewed in adolescents with unwanted pregnancies.

\section{RESEARCH METHODS}

Methodology in this review uses scoping review method. Scoping review is a method that is carried out to meet various objectives including being able to examine the size, range of exploration or variation of data and characteristics of research on a theme or question that will be assessed on a systematic review to summarize the findings of heterogeneous knowledge. (Tricco et al., 2016). The Scoping Review used a grouping review suggested by Arksey and O'Malley and was later further developed by Levac et al. There are stages used to identify scoping review questions, identify relevant articles, select or select relevant articles, and map data (Arksey \& O’Malley, 2005) (Levac et al., 2010) as follows : 


\section{Identify Scoping Questions Review}

This review uses the Population, Exsposure, Outcome, and study design (PEOs) frameworks to develop topical focus in literature search in scoping review

questions. PEOS helps to identify key concepts in the focus of the question in developing appropriate search terms to describe the problem as well as determining inclusion and exclusion criteria (Bettany-Saltikov, 2012).

\begin{tabular}{llll} 
& \multicolumn{2}{c}{ Table.1 Framework PEOs } \\
\hline $\mathbf{P}$ & $\mathbf{E}$ & $\mathbf{O}$ & $\mathbf{S}$ \\
\hline $\begin{array}{l}\text {-Adolescent } \\
\text { - Teenage }\end{array}$ & unwanted pregnancy & Exprerience & Qualitative and Quantitative \\
\hline
\end{tabular}

\section{Identify Relevant Articles}

This review uses four databases namely Pubmed, Proquest, Sciendirect, Wiley and google schoolar (grey literature) search engine using keywords that have been identify by the author related to the topic of scoping in the search process. Keywords used to search for articles are ("Adolescent" OR "Teenage") AND ("unwanted pregnancy" OR " unintended pregnancy") AND ("experience" OR "opinion" OR "view" OR "perspective").

In this review process the author identifies relevant articles using the following inclusion and exclusion criteria:

\begin{tabular}{ll}
\multicolumn{2}{c}{ Table.2 Inclusion Criteria and Exclusion Criteria } \\
\hline Inclusion Criteria & Exclusion Criteria \\
\hline Articles 2009-2019 & Opinion articles \\
\hline English and Indonesian publicist articles & Publication manuscript \\
\hline Original article & Document report/ policy draf/ guideline from \\
& WHO/ certain formal organization \\
\hline
\end{tabular}

\section{Selection of elevant Studies}

The data filtering process is using Preferred Reporting Items For Systematic Reviews and Meta-Analyses (PRISMA, 2015). PRISMA is considered appropriate because its use can improve the quality of publication reporting (Peters et al., 2015).

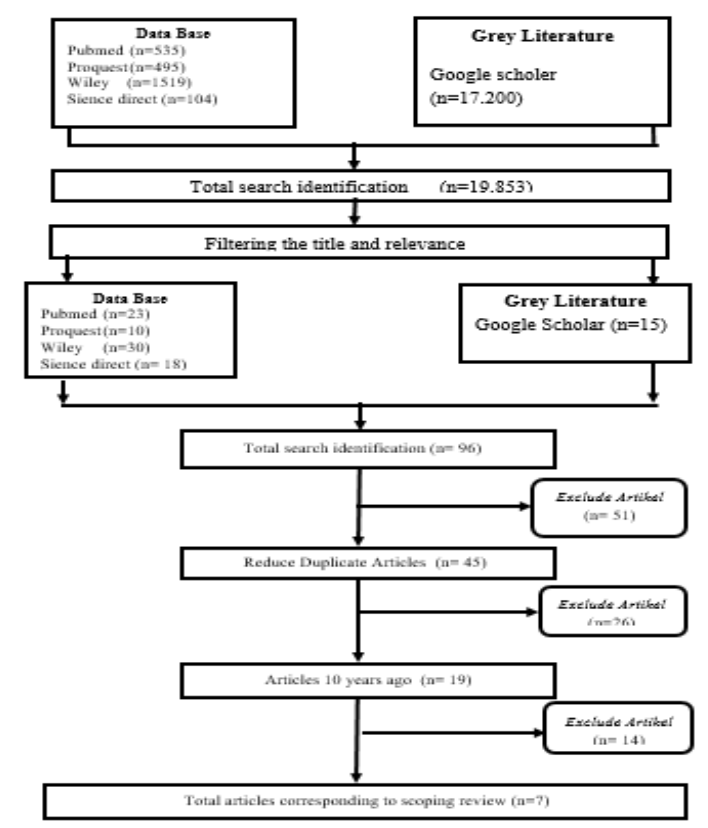

Figure 1. Prisma Flowchart 


\section{Charting Data}

Table.3 Charting Data

\begin{tabular}{|c|c|c|c|c|c|c|c|}
\hline No & $\begin{array}{l}\text { Title/Author/Year/Val } \\
\text { ue }\end{array}$ & Country & Aim & $\begin{array}{l}\text { Types of } \\
\text { Research }\end{array}$ & Collection Data & $\begin{array}{l}\text { Participants/ } \\
\text { Size/Sample }\end{array}$ & Results \\
\hline 1. & 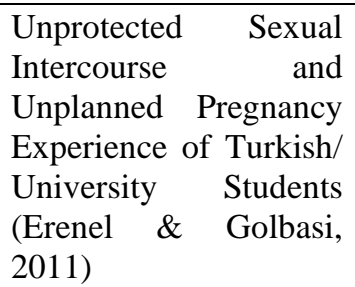 & Turki & $\begin{array}{l}\text { This study tested the } \\
\text { experience of sexual } \\
\text { intercourse without } \\
\text { contraceptives }\end{array}$ & Cros-sectional & Questionnaire & $\begin{array}{l}\text { Average student age } \\
18 \text { years }\end{array}$ & $\begin{array}{l}\text { Teenagers have sexual intercourse for the first } \\
\text { time at the age of } 18 \text {. Adolescents who used } \\
\text { contraceptives as much as ( } 36.4 \%) \text { using } \\
\text { condoms }(74.0 \%) \text { experiencing an unwanted } \\
\text { pregnancy }(8.6 \%) \text { and }(73.9 \%) \text { perform an } \\
\text { abortion. }\end{array}$ \\
\hline 2. & $\begin{array}{l}\text { To keep or not to keep? } \\
\text { Decision making in } \\
\text { adolescent pregnancies } \\
\text { in Jamestown, Ghana/ } \\
\text { (Bain et al., 2019) }\end{array}$ & Ghana & $\begin{array}{l}\text { To understand the } \\
\text { decision (to maintain or } \\
\text { discontinue) the factors } \\
\text { and experiences } \\
\text { surrounding pregnancy } \\
\text { in adolescents. }\end{array}$ & Qualitative & $\begin{array}{l}\text { Indepth } \\
\text { Interview }\end{array}$ & Teenagers aged 13-19 & $\begin{array}{l}\text { Most teenagers }(96.1 \%) \text { contraceptives and no } \\
\text { one uses contraceptives before becoming } \\
\text { pregnant. Most teenagers }(87.0 \%) \text { have an unsafe } \\
\text { abortion experience. Barriers to accessing safe } \\
\text { abortion services include low awareness of } \\
\text { abortion laws, high costs and distrust of health } \\
\text { care providers. Teenagers who choose to } \\
\text { continue pregnancy because of their own desires } \\
\text { and socio-cultural. }\end{array}$ \\
\hline 3. & $\begin{array}{l}\text { Adolescents' responses } \\
\text { to an unintended } \\
\text { pregnancy in Ghana: A } \\
\text { qualitative study/ } \\
\text { (Aziato et al., 2016a) }\end{array}$ & Ghana & $\begin{array}{l}\text { To investigate the } \\
\text { experiences and } \\
\text { perceptions of } \\
\text { adolescents who } \\
\text { have experienced } \\
\text { unwanted pregnancies } \\
\text { and had abortions. }\end{array}$ & Qualitative & $\begin{array}{l}\text { Focus group } \\
\text { discussion }\end{array}$ & $\begin{array}{l}\text { Adolescents, ages } 10- \\
19 \text { who are } \\
\text { experiencing } \\
\text { unwanted } \\
\text { pregnancies }\end{array}$ & $\begin{array}{l}\text { Teens report that when they have an unwanted } \\
\text { pregnancy will feel sad, depressed, remorseful } \\
\text { and male partners reject the pregnancy and } \\
\text { advise for an abortion. Some parents will be } \\
\text { "angry" and alienate the teenager to avoid stigma } \\
\text { and shame in society. }\end{array}$ \\
\hline 4. & $\begin{array}{l}\text { Decisionmaking } \\
\text { Regarding Unwanted } \\
\text { Pregnancy among } \\
\text { Adolescents in Mexico } \\
\text { City: A Qualitative } \\
\text { Study/ (Tatum et al., } \\
\text { 2012) }\end{array}$ & Mexico & $\begin{array}{l}\text { To find out the role of } \\
\text { friends, partners, } \\
\text { family, and healthcare } \\
\text { providers in decision- } \\
\text { making to maintain or } \\
\text { terminate a pregnancy }\end{array}$ & Qualitative & $\begin{array}{l}\text { FGD } \\
\text { Indepth } \\
\text { Interview }\end{array}$ & $\begin{array}{l}\text { Teens } 13 \text { and } 17 \\
\text { years old }\end{array}$ & $\begin{array}{l}\text { The results suggest that a fair relationship of } \\
\text { gender power and low social and economic status } \\
\text { may increase risks. Interventions to prevent } \\
\text { teenage pregnancy need to be adapted to } \\
\text { socioeconomic status because some teens see } \\
\text { pregnancy as a way to have a safe future. }\end{array}$ \\
\hline
\end{tabular}


5. The Turning Point in Malaysia

Unwanted Teenage

Pregnancy:

Psychoemotional

Perspective/(Nor et al.,

2019)

6. Teenage Experience of

Pregnancy and the

Parents' and Partners'

Reactions: A

Malaysian Perspective

/(Saim et al., 2014)

7. Women experience

with unplanned

pregnancy and abortion

in Kenya: A qualitative

study/(Jayaweera et al.,

2018)

to gain an
understanding of the
adolescent experience
with unwanted
pregnancies
To find out the
experiences of
adolescents in relation
to the reactions of
parents and spouses
related to unwanted
pregnancies

Kenya

To find out the experiences of adolescents related to unwanted pregnancy experiences

\section{Qualitative \\ Interview \\ 17 year olds}

The results of this study discussed three themes, namely self-transformation, transition to motherhood and spiritual strengthening.
Qualitative
Qualitative Interview
Teens ages 13 and 17
Adolescents described a variety of factors that influenced the experience with abortion in the community and a lack of knowledge of reproductive health information as well as a lack of access to contraceptives that could lead to unwanted pregnancies. Pregnant teens will seek information about abortion because of low education. 
Critical Apraisal is a process of criticism or assessment of research evidence to assess the quality of a research methodology in determining the extent to which a study has discussed research design, behavior, and analysis (JBI, 2017). In the selection of articles using Grades A and B.

\section{Presentation of data / results, discussions and conclusions}

At this stage, data export is carried out in 7 articles to group the themes obtained.

\begin{tabular}{|c|c|}
\hline THEME & SUB THEMES \\
\hline \multirow[t]{2}{*}{ Decision-making } & 1. Continuing pregnancy ${ }^{4,5}$ \\
\hline & 2. Terminating the pregnancy ${ }^{4,3}$ \\
\hline \multirow[t]{5}{*}{ Social Support } & 1. Role of self ${ }^{5}$ \\
\hline & 2. Role of family ${ }^{3,4,5}$ \\
\hline & 3. The role of friends ${ }^{4}$ \\
\hline & 4. The role of health workers ${ }^{3,4}$ \\
\hline & 5. Spouse role ${ }^{5,4}$ \\
\hline \multirow[t]{4}{*}{ Psychological Impact } & 1. $\mathrm{Sad}^{3,4,5}$ \\
\hline & 2. Depression 4,5 \\
\hline & 3. Regret $^{2}$ \\
\hline & 4. Not happy ${ }^{3}$ \\
\hline \multirow[t]{2}{*}{ Transition to motherhood } & 1. Receiving the baby ${ }^{5}$ \\
\hline & 2. Emotional 4,5 \\
\hline
\end{tabular}

Description: the number is the article code in the charting data

\section{RESULTS AND DISCUSSION}

\section{A. Results}

1. Characteristics of the Article

Characteristics of the article of the country where the research was conducted, based on the design of the research as well as the quality of the article based on the assessment of Critical appraisal tools Joana Briggs Institute.

a) Grouping Articles by Country

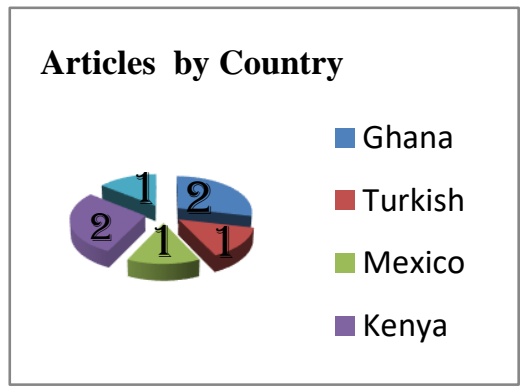

Figure.2 Articles are from developing countries

\section{b) Grouping Articles Based on Research Design}

Articles by Study Design

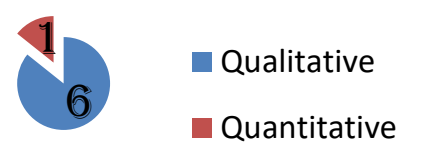

Figure.3 The majority of articles are by qualitative research design 
c) Grouping By Grade

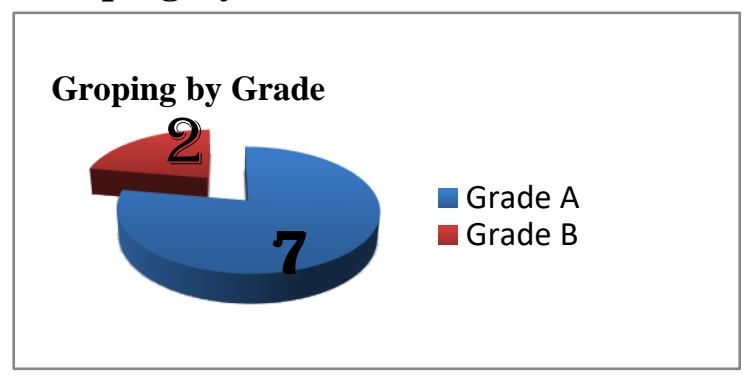

\section{Decision Making}

Figure.4 Grade A and B

a) Continuing Pregnancy

Almost all teenagers take the decision to terminate or continue their pregnancy. Teenagers are not ready to be a mother at a young age and want to end a pregnancy. Although faced with two options that have consequences and confusion to choose which one to choose. In addition, some teenagers are able to identify what to do regardless of the final decision to be taken. In youth decision making requires advice and support from various parties (Tatum et al., 2012).

Initially all teenagers wanted to end their pregnancy by trying unsafe abortion techniques such as eating pineapple, buying medicines over the internet, eating yeast, drinking a mixture of paracetamol and carbonated beverages. But towards the end of pregnancy (the third trimester), adolescents begin to form emotional bonds and love the child. Some teenagers start rubbing their stomachs gently, talking and even singing to their babies. Adolescents who maintain pregnancy are the right decision and at the beginning of pregnancy plan to abort the pregnancy. But the intention was cancelled due to an emotional bond. Therefore, the teen decided to take care of the baby and obtain approval from the family (Nor et al., 2019).

\section{b) Terminating Pregnancy}

Unsafe sexual experiences and the use of methods whose effects are inaccurate are the causes of unwanted pregnancies. When a partner (partner) knows pregnancy usually refuses pregnancy because it thinks it will have a bad impact on social life in the long and short term. With this rejection, teenage girls tend to decide to terminate their pregnancy (Erenel \& Golbasi, 2011). Adolescents report the experience of performing abortions by taking potions, drugs, alcohol that cause teenagers to experience pain until unconsciousness (Bain et al., 2019).

In some cases couples are not involved, teenagers choose to terminate a pregnancy without their partner's knowledge but in some cases the teen rejects the pregnancy even the pregnant teen attempts to abort the pregnancy (Aziato et al., 2016). That's what encourages teenagers to make decisions and not tell their partners. Most teens choose not to involve parents or other adults when they find out they are pregnant (Tatum et al., 2012). Teenagers say they fear the reaction of parents who will be angry, stressed, disappointed, worried 
and so sad when they find out that they did not tell about her pregnancy in the first place (Aziato et al., 2016).

\section{Social Support}

\section{a) Family Support}

Support from parents and peers is a very important support because it can influence the decision to maintain or terminate a pregnancy. Where the father is a decision-maker that can influence the final decision for pregnant teenagers. The teen's decision on her pregnancy is determined by the extent to which the teen relies on family support especially the mother due to her previous pregnancy experience. (Bain et al., 2019). Parents have a strong influence to make decisions or actions when the teenager will intend to perform a termination of pregnancy by accepting the pregnancy of the child and will continue to care together (Tatum et al., 2012).

\section{b) Friend Support}

Most of the teens involved at least one colleague (family member or friend) will help to explore emotions about pregnancy. The role of parents in helping to make decisions to maintain pregnancy and choose a place to give birth. The presence of friends helps teens overcome feelings of shame or uncertainty in decision making, and helps provide information to know pregnancy quickly (early). Friends of the teen recommend how to get a pregnancy test kit or give it directly. Once pregnancy is known, teen friends continue to provide emotional support by providing choices and helping determine how they will end the pregnancy or continue it (Tatum et al., 2012).

\section{c) Couples Support}

Couples play an important role. Most teenagers discuss pregnancy with a partner when suspected or after informing their partner, some teenagers do not communicate their pregnancy to their partner/ partner. This is because teenagers do not have a commitment (seriousness) in their relationship. The relationship has ended and she feels there is no need to involve the couple in decision making (Tatum et al., 2012).

\section{Psychological Impact}

\section{a) Sad}

Some teenagers showed a very emotional initial reaction which was shock, crying, despair, anger with themselves for not thinking that this would happen (Tatum et al., 2012). In addition, teenagers assume that teenagers who are pregnant will happen something bad about their pregnancy because getting pregnant while in school is often considered inappropriate. Teenagers do not expect the number of her pregnancy because when going to the hospital to do examinations teenagers are shocked, embarrassed Teenagers feel ashamed because their education is cut off and can not achieve their goals. Some people assume that teenagers have multiple sexual partners before becoming pregnant and if they sleep more than one man it will not know who impregnated them. Some teenagers think that pregnant teenage girls will 
intend to terminate their pregnancies because they are not ready (Aziato et al., 2016).

\section{b) Depression}

When the teenager first learned of her pregnancy they refused the pregnancy and wanted to end it. They only think about how her life is, social response and the future without thinking about the baby she is carrying. In this situation the majority of teenagers are depressed, unprepared to be parents at a very young age, heavy responsibility, feeling hopeless and some decide to end their lives (Tatum et al., 2012). Some teenagers described an initial reaction that was very emotional when knowing that she was pregnant would be shocked and angry with herself, for not thinking that this would happen, crying and crying, not knowing what to do, and intending to kill herself (Nor et al., 2019).

\section{c) Remorse}

Most teenagers with experience of performing abortions do not feel sorry about the decisions taken and will make similar choices under similar conditions in the future. Except for people who have been forbidden by their parents to end their anesthroanity. While regret is expressed some teenagers compared to the chances of losing in terms of continuing pregnancy (Bain et al., 2019).

\section{Obstacles}

\section{a) Lack of Education}

Adolescents are described as aware of the dangers of abortion as well as the risk of failure of contraceptive methods during ongoing pregnancies and delays preventing complications. The teen ends the pregnancy with an abortion because she doesn't want the mother to know about the pregnancy. Some teenagers use methods such as hangers or other metal objects to remove the fetus. Teenagers reported performing abortions by purchasing prescription drugs, herbalists, and midwives. In addition, teenagers perform unsafe abortions assisted by a person to remove the fetus (Jayaweera et al., 2018).

\section{b) Access to Services}

Teens say they feel comfortable talking over the phone about abortion and reproductive health issues. The teen reportedly worried a friend might go and spread her pregnancy. The teen was briefed by friends and family about the abortion information and learned that some of the information received from the source was unsafe. Overall adolescents expressed a desire to get information and training on reproductive health. In addition, teenagers can share accurate information with friends and the environment (Jayaweera et al., 2018).

\section{c) Self-distrust}

Some teenagers believe that hospitals offer services available to teens who can afford to pay a doctor with high fees to have an abortion in the 
hospital. Teenagers generally believe that abortion is available in hospitals that can lead to pregnancy and cause death. Additionally reasons for long journey distances, managing logistics scheduling, and travel-related financial issues (Jayaweera et al., 2018).

\section{Transition to Motherhood}

\section{a) Receiving her baby}

The majority of adolescents at the beginning of pregnancy still respond with rejection of her pregnancy and desire to terminate the pregnancy but after the second trimester of pregnancy the teen begins to feel an emotional attachment to the baby she is carrying, the desire to take good care of their baby as the process of transitioning to motherhood. During the early stages

of pregnancy many of them feel mixed emotions but they then take the wisdom of what has happened and see their baby as a hope for a better future. They mention that feelings come from within their hearts and it is natural for them to take care of their own child. They faced a very dilemma when revealing their decision to reveal to her parents that she planned to look after her baby during the third trimester. They are very happy to know that their parents gave their consent to keep the pregnancy but other parents of teenagers will force their pregnant child to marry another man who is not the biological father of the baby conceived by the child so that the baby conceived has a complete identity and family (Nor et al., 2019).

\section{b) Not Accepting Pregnancy}

Teenagers reveal that what affects the process of taking a decision is parents (mother and father), friends and family, for example the father asks to have an abortion by threatening not to admit if the pregnancy is not terminated and still maintains the pregnancy. Teen chooses to have abortion due to lack of support from partner and desire to continue education (Bain et al., 2019).

Teenagers who become pregnant outside of family marriage will feel ashamed, worried and anxious to keep or keep the pregnancy a secret and unable to accept pregnancy. In addition the couple denied pregnancy and accused her of having an affair with another man. The couple refused on the grounds of having no job or financial instability, without giving any reason, and both families agreed to marry. On the other hand, fathers who know pregnant teenagers will refuse, ignore, provide no solution, even be humiliated and threatened by a partner so as not to be responsible. (Saim et al., 2014).

\section{B. Discussion}

\section{Decision Making}

Regardless of the influence of parents and peers in deciding to maintain or terminate a pregnancy. Decision-making overrides shared decision-making, in which fatherhood is the primary role in making decisions. Adolescents in making the decision to terminate or maintain a pregnancy depends on family support which is the extent to which it can have the influence to make decisions. Some of the reasons teens choose not to continue pregnancy and have abortions is 
because couples refuse to take responsibility, under pressure from parents (Bain et al., 2019).

Most teenagers make decisions and get informed about the choice to continue or terminate a pregnancy. Adolescents show an ability to make decisions and most need the help of others and in some cases other people's involvement leads to unwanted outcomes by adolescents. Thus showing the various roles played by others in the decision making of teenage pregnancy. Most teens seek support from others and evaluate the risks and benefits of pregnancy (Tatum et al., 2012). This research is (Palomino et al., 2011) that is in case of pregnancy does not chill teenagers take their own decisions or involve a partner. In addition, families, especially parents also play a role in decision making.

\section{Psychological Support}

Support from parents, peers, and partners (couples) is an important support in adolescents that can influence a teenager's decision to terminate or maintain a pregnancy. Supported by (Tatum et al., 2012) research is the involvement of supportive parents in decision making. The presence of friends helps overcome the feeling of embarrassment or uncertainty of decision making and helps share information so that pregnancy can be quickly noticed early. In addition, the importance of couples' involvement in decision making in order for teenagers to maintain pregnancy and be responsible. This research is (Ardhia et al., 2018) namely the need for support in adolescents who experience unwanted pregnancy, especially the need for social support from health workers during pregnancy that can increase the motivation of teenagers to maintain and carry out their pregnancy properly.

\section{Psychological Impact}

The psychological impact experienced by teenagers is that adolescent education is cut off and unable to achieve its goals, experiencing depression, and deciding to end its life. This research is (Nor et al., 2019) teenagers described a very emotional initial reaction when knowing that she was pregnant would be shocked and angry with herself, for not thinking that this would happen to her and not knowing what to do, feeling hopeless, and intending to kill herself. This research is in line with the research conducted (Bahk et al., 2015) teenagers who experience unwanted pregnancy will experience depression and stress.

\section{Obstacles}

Adolescents with unwanted pregnancies lead to low education, difficulty getting service information, and not getting a job. Information on contraception and the dangers of abortion may reduce pregnancy in adolescents so that they can continue their education, well-being, and get a job. Today, abortion is seen as a way to avoid the negative social and economic consequences of an unwanted pregnancy. The role of society in preventing and reducing abortion is by increasing the empathy of the community in adolescents who seek information about abortion, set a good example in adolescents, and increasing activities to reduce the desire of adolescents to perform abortions (Jayaweera et al., 2018). This research is (Mayun et al., 2017) pregnancy with unwanted among adolescents 
due to lack of sexual and reproductive health education both at home and at school, as well as lack of self-efficacy.

\section{Transition to Motherhood}

Most teenagers receive their pregnancies due to emotional attachment to the baby they are carrying, a desire to take good care of the baby. The appearance of feelings from the heart to take care of their own child and very excited when knowing that his parents gave consent to them to keep the pregnancy. Supported research from (Nor et al., 2019) after the second trimester of her pregnancy teenagers began to feel an emotional attachment to the baby she was carrying, the desire to take good care of their baby as the process of transitioning to motherhood. During the early stages of pregnancy many of them feel mixed emotions but they then take the wisdom of what has happened and see their baby as a hope for a better future. Teenagers mention that feelings come from within their hearts and it is natural for them to take care of their own child.

\section{CONCLUSION}

In decision making teenagers need advice and support from various parties, namely family, friends, spouses and the environment. The support provided to adolescents is what can influence a teenager's decision to maintain or terminate a pregnancy.

\section{REFERENCES}

Ardhia, D., Wahyuni, B., \& Nisman, W. A. (2018). Adolescents' experiences and needs of social support from health staff in pregnancy in Yogyakarta. BKM Journal of Community Medicine and Public Health Universitas Gadjah Mada, 34(1), 25-32.

Arksey, H., \& O’Malley, L. (2005). Scoping studies: Towards a methodological framework. International Journal of Social Research Methodology: Theory and Practice, 8(1), 19-32. https://doi.org/10.1080/1364557032000119616

Aziato, L., Hindin, M. J., Maya, E. T., Manu, A., Amuasi, S. A., Lawerh, R. M., \& Ankomah, A. (2016). Adolescents' Responses to an Unintended Pregnancy in Ghana: A Qualitative Study. Journal of Pediatric and Adolescent Gynecology, 29(6), 653-658. https://doi.org/10.1016/j.jpag.2016.06.005

Bahk, J., Yun, S. C., Kim, Y. mi, \& Khang, Y. H. (2015). Impact of unintended pregnancy on maternal mental health: A causal analysis using follow up data of the Panel Study on Korean Children (PSKC). BMC Pregnancy and Childbirth, 15(1), 1-12. https://doi.org/10.1186/s12884-015-0505-4

Bain, L. E., Zweekhorst, M. B. M., Amoakoh-Coleman, M., Muftugil-Yalcin, S., Omolade, A. I. O., Becquet, R., \& De Cock Buning, T. (2019). To keep or not to keep? Decision making in adolescent pregnancies in Jamestown, Ghana. PLoS ONE, 14(9), 1-18. https://doi.org/10.1371/journal.pone.0221789

Bettany-Saltikov, J. (2012). How to do a systematic literature review in nursing : a stepby-step guide. University Campus Suffolk (UCS), 77(6), 276-288. https://doi.org/10.4276/030802214X14018723137959 
CDC. (2019). Unintended Pregnancy _ Unintended Pregnancy _ Reproductive Health _ $C D C$.

https://www.cdc.gov/reproductivehealth/contraception/unintendedpregnancy/index .htm

Domingos, S. R. da F., Merighi, M. A. B., de Jesus, M. C. P., \& de Oliveira, D. M. (2013). The experience of women with abortion during adolescence as demanded by their mothers. Revista Latino-Americana de Enfermagem, 21(4), 899-905. https://doi.org/10.1590/S0104-11692013000400010

Erenel, A. S., \& Golbasi, Z. (2011). Unprotected sexual intercourse and unplanned pregnancy experience of Turkish university students. Sexuality and Disability, 29(1), 75-80. https://doi.org/10.1007/s11195-010-9186-0

Fahmida Shirin Papri, Zubaida Khanam, Sarwat Ara, M. B. P. (2016). Papri. Chattagram Maa-O-Shishu Hospital Medical College Journal, 15(1), 53-56.

Finer, L. B., \& Zolna, M. R. (2020). Shifts in Intended and Unintended Pregnancies in the United States , 2001 - 2008. 104, 43-49. https://doi.org/10.2105/AJPH.2013.301416

Jayaweera, R. T., Ngui, F. M., Hall, K. S., \& Gerdts, C. (2018). Women's experiences with unplanned pregnancy and abortion in Kenya: A qualitative study. PLoS ONE, 13(1), 1-13. https://doi.org/10.1371/journal.pone.0191412

JBI. (2017). Checklist for Randomized Controlled Trials. Joanna Briggs Institute, 1-9. http://joannabriggs.org/research/critical-appraisal-tools.html

Kirchengast, S. (2016). Teenage Pregnancies: A Worldwide Social and Medical Problem. An Analysis of Contemporary Social Welfare Issues. https://doi.org/10.5772/65462

Levac, D., Colquhoun, H., \& O'Brien, K. K. (2010). Scoping studies: Advancing the methodology. Implementation Science, 5(1), 1-9. https://doi.org/10.1186/17485908-5-69

Lidaka, L., Viberga, I., \& Stokenberga, I. (2015). Risk factors for unwanted pregnancy and subsequent abortion among women aged 16 to 25 years in Latvia. European Journal of Contraception and Reproductive Health Care, 20(3), 201-210. https://doi.org/10.3109/13625187.2014.993026

Mandy S. Colesa, \& , Kevin K. Makinob, and N. L. S. (2012). NIH Public Access. Bone, 23(1), 1-7. https://doi.org/10.1016/j.contraception.2011.03.008.Contraceptive

Mayun, K. A. W., Ani, L. S., \& Suariyani, N. L. P. (2017). Causes of unwanted pregnancy among adolescents in Bali Province: a qualitative study. Public Health and Preventive Medicine Archive, 5(2), 90. https://doi.org/10.15562/phpma.v5i2.20

Nor, A. M., Shah, S. S. A., Balasingam, U. A. / P., \& Zainudin, Z. N. (2019). The Turning Point in an Unwanted Teenage Pregnancy: A Psycho-Emotional Perspective. Malaysian Journal of Medicine and Health Sciences, 15(SUPP1), 30-36. 
Palomino, N., Padilla, M. R., Talledo, B. D., Mazuelos, C. G., Carda, J., \& Bayer, A. M. (2011). The social constructions of unwanted pregnancy and abortion in lima, Peru. Global Public Health, 6(SUPPL.1), 37-41. https://doi.org/10.1080/17441692.2011.590813

Peters, J. P. M., Hooft, L., Grolman, W., \& Stegeman, I. (2015). Reporting quality of systematic reviews and meta-analyses of otorhinolaryngologic articles based on the PRISMA statement. PLoS ONE, 10(8), 1-11. https://doi.org/10.1371/journal.pone.0136540

PRISMA. (2015). Preferred reporting items for systematic review and meta-analysis protocols (PRISMA-P) 2015 statement. Revista Espanola de Nutricion Humana y Dietetica, 20(2), 148-160. https://doi.org/10.1186/2046-4053-4-1

Saim, N. J., Dufåker, M., \& Ghazinour, M. (2014). Teenagers’ Experiences of Pregnancy and the Parents' and Partners' Reactions: A Malaysian Perspective. Journal of Family Violence, 29(4), 465-472. https://doi.org/10.1007/s10896-014-9595-4

Soura, A. B., Lankoande, Y. B., Sanogo, S., Compaore, Y., \& Senderowicz, L. (2018). Understanding premarital pregnancies among adolescents and young women in Ouagadougou, Burkina Faso. Cogent Social Sciences, 4(1), 1-18. https://doi.org/10.1080/23311886.2018.1514688

Tatum, C., Rueda, M., Bain, J., Clyde, J., \& Carino, G. (2012). Decisionmaking regarding unwanted pregnancy among adolescents in Mexico City: a qualitative study. Studies in Family Planning, 43(1), 43-56. https://doi.org/10.1111/j.17284465.2012.00301.x

Tricco, A. C., Lillie, E., Zarin, W., O’Brien, K., Colquhoun, H., Kastner, M., Levac, D., Ng, C., Sharpe, J. P., Wilson, K., Kenny, M., Warren, R., Wilson, C., Stelfox, H. T., \& Straus, S. E. (2016). A scoping review on the conduct and reporting of scoping reviews. BMC Medical Research Methodology, 16(1), 1-10. https://doi.org/10.1186/s12874-016-0116-4

Tuan, N. T. V. and P. C. (2017). Fctors influencing unintended pregnancy and ABORTION AMONG UNMARRIED YOUTH IN VIETNAM: Alitrature review,2017. 3(2), 3-16.

UNFPA. (2019). Child marriage | UNFPA - United Nations Population Fund. In United Nations Population Fund. https://www.unfpa.org/child-marriage

WHO. (2014). Adolescent pregnancy fact sheet. Adolescent Pregnancy Fact Sheet, 1. http://apps.who.int/iris/bitstream/10665/112320/1/WHO_RHR_14.08_eng.pdf\%0A www.who.int/reproductivehealth

WHO. (2020). Adolescent pregnancy. In Cahiers de sexologie clinique (Vol. 16, Issue 100, pp. 17-179). World Health Organization, Alliance for Health Policy and Systems Research. https://www.who.int/news-room/fact-sheets/detail/adolescentpregnancy 